\title{
La financiación de las universidades hispanas durante el período medieval (siglos XIII-XV)
}

\author{
The Funding of Hispanic Universities \\ in the Middle Ages (13 ${ }^{\text {th }}-15^{\text {th }}$ Centuries)
}

\author{
Susana Guijarro González* \\ Universidad de Cantabria \\ ORCID ID: 0000-0002-0082-1541
}

$\begin{array}{ll}\text { Recibido: } & 18 / 02 / 2021 \\ \text { Aceptado: } & 23 / 04 / 2021\end{array}$

DOI: https://doi.org/10.20318/cian.2021.6156

Resumen: Este artículo analiza los modelos de financiación de las universidades medievales de la Corona de Castilla y de la Corona de Aragón durante su primera andadura en los siglos medievales. La comparación entre dichos modelos revela diferencias y similitudes. Las diferencias observadas están relacionadas con el papel desempeñado por la monarquía, el pontificado, los obispos junto con sus cabildos catedralicios y los gobiernos municipales en su origen y evolución durante la Baja Edad Media. Las similitudes atañen a la administración y tipología de las fuentes de ingreso que demostraron ser insuficientes e
Abstract: This paper studies the funding models of medieval universities in the Crowns of Castile and Aragon during their initial stage in the Middle Ages. The comparison between the models reveals differences and similarities. The former are related to the role that the monarchy, the pontificate, bishops and their cathedral chapters, and municipal corporations played in their origin and development in the Late Middle Age. The similarities are seen in the administration and the types of sources of income, which proved to be insufficient and unstable. The financial weakness of the medieval universities meant

*susana.guijarro@unican.es.

Algunos de los datos de este artículo han sido tomados de las fuentes eclesiásticas reunidas en el contexto del desarrollo del Proyecto de I+D, PID2019-108273GB-I00 del cual la autora es investigadora principal. 
inestables. La debilidad económica de estas universidades medievales hizo necesario el recurso continuo a la protección pontificia. Por otra parte, el compromiso de las ciudades y las oligarquías urbanas que las gobernaban para con esta nueva institución educativa no fue siempre igual de firme y efectivo.

Palabras clave: financiación-universidades; coronas de Castilla y Aragón; fuentes de ingreso-gastos; siglos XIII-XV. that they constantly needed to resort to pontifical protection. Moreover, the cities and urban oligarchies who ruled them were not always committed firmly and effectively to these new educational institutions.

Keywords: university funding; Medieval Castilian and Aragonese Crowns; sources of income and expenses; $13^{\text {th }}-15^{\text {th }}$ Centuries.

La Universidad o Estudio General como institución genuina de la enseñanza superior nació en los territorios de la España medieval a la par que en el resto del Occidente europeo pero con diferentes ritmos. Mientras que en los reinos de Castilla y de León (Corona de Castilla desde 1230) los Estudios generales de Palencia, Salamanca y Valladolid (referencia de 1293) aparecieron en los primeros decenios del siglo XIII como sus grandes homólogas europeas (Bolonia, París y Oxford), en la Corona de Aragón se demoraron hasta el siglo XIV (Lérida y Huesca).

La financiación regia y eclesiástica de las primeras universidades castellanas frente a la iniciativa municipal de las aragonesas

Historiográficamente, se ha puesto el acento en el mayor protagonismo que tuvo la monarquía castellana si se compara con la aragonesa, tanto en la creación como en la financiación de sus universidades medievales. La escasez de documentos fundacionales que caracteriza la infancia de las universidades castellanas no permite ir más allá de la formulación de hipótesis con mayor o menor aceptación. Esta afirmación puede extenderse a los tres primeros y únicos Estudios generales que florecieron en Castilla entre los siglos XIII al $\mathrm{XV}$ y es especialmente cierta para la primera universidad hispana (Palencia) con un siglo escaso de vida (ca. 1180-1275), así como para la de Valladolid que perduró. En la de Palencia, al igual que en la de Salamanca (ca. 1218), han sido los relatos cronísticos del obispo Lucas de Tuy (+1249) y del Arzobispo de Toledo, Jiménez de Rada (+1247), los que ha contribuido a reforzar el protagonismo regio. Ambos prelados inscribieron sus fundaciones en el contexto de la política de Alfonso VIII y de Alfonso IX para con sus reinos de 
Castilla y León respectivamente ${ }^{1}$. Sin embargo, es preciso matizar que el protagonismo regio se tradujo en el impulso dado a la iniciativa de los obispos del entorno real. No hay que olvidar que la Iglesia y la monarquía castellana se hallaron aún durante el primer cuarto del siglo XIII financieramente comprometidas con las campañas militares de conquista de las ciudades andaluzas bajo dominio musulmán, además de los propios conflictos internos que se sucedieron entre los reinos cristianos.

En el surgimiento del Estudio palentino se ha querido ver en el Obispo Raimundo (1148-1183) el germen de la iniciativa que apoyaría Alfonso VIII, pero no existen documentos en los que intervenga el monarca ${ }^{2}$. Los frentes bélicos que tenía abiertos no facilitaron seguramente la dedicación de las tercias reales (rentas eclesiásticas concedidas por la Iglesia hispana a los reyes para llevar a cabo la guerra contra los musulmanes) a la dotación de los salarios de los maestros que enseñaban en Palencia. Con Fernando III y su canciller, el Obispo Tello Téllez de Meneses, se dispone de evidencias de la obtención de rentas eclesiásticas suficientes para mantener el Estudio general entre 1214 y 1246. Entre 1220 y 1225, ambos lograron del Pontífice Honorio III la cuarta parte de los diezmos de las iglesias de la diócesis de Palencia (1220) y dos prórrogas ,por cinco años, de esta concesión para cubrir el salario de al menos cuatro cátedras (1221 y 1225) ? $^{3}$ No cabe pensar en más partidas de gasto por entonces ya que, tanto las dependencias catedralicias como las casas propiedad del cabildo catedralicio, harían las veces de escuelas y residencia de maestros y estudiantes. Por otra parte, la condición de clérigos (bastaba con las órdenes menores) de la inmensa mayoría de los miembros del Estudio les hacía ya receptores de beneficios eclesiásticos, eso sí, con cuantías muy desiguales. Pero el lastre del estado de guerra continuo que se activó de nuevo desde 1224 hasta la conquista de Sevilla (1248) debió sumir al Estudio de Palencia en la decadencia ya que no vuelven a producirse noticias del mismo, con la excepción de una bula de Urbano $V$ en virtud de la cual se le otorgaban a sus miembros los mismos

${ }^{1}$ Rodrigo Jiménez de Rada, De rebus hispaniae, Siglo XIII, Vicente Beltrán de Heredia, Cartulario de la Universidad de Salamanca, 1218-1600 (en adelante, CUS), I, (Salamanca: Universidad de Salamanca. 1970), p. 600. Lucas de Tuy, Chronicon Mundi, ca. 1238, ed. de Emma Falque, (Turnhout : Brepols 2003).CUS I, doc. 11, 596.

${ }^{2}$ Gonzalo Martínez Díez, "Palencia, primera universidad de España" en El Estudio General de Palencia. Historia de ocho siglos de la Universidad española, Ed. Margarita Torremocha Hernández, (Valladolid: Universidad de Valladolid-Instituto Universitario Simancas, 2012), 58.

${ }^{3}$ Bulas de Honorio III, ed. de Jesús San Martín Payo, La antigua Universidad de Palencia (Madrid: Afrodisio Aguado, 1942), doc. I (30/12/1220), doc. VII (18/03/1221) y doc. $8(17 / 01 / 1225)$. 
privilegios e inmunidades de que disfrutaba la Universidad de Paris ${ }^{4}$. No hay que desdeñar la competencia creciente que supuso la vecina villa de Valladolid, cuyo crecimiento urbano y condición de sede reiterada de la corte real, se manifestaron con vigor desde la segunda mitad del siglo XIII, a pesar de no ser cabeza de diócesis como Palencia. No hay pruebas documentales, sin embargo, que sustenten la hipótesis de un traslado de la Universidad de Palencia a la ciudad del Pisuerga.

Mejor suerte corrió la Universidad de Salamanca que nació en el reino de León con presupuestos de partida similares a la de Palencia. Sede episcopal y un cabildo catedralicio que respaldaría el desarrollo de unas escuelas catedralicias como caldo de cultivo previo. Bien es cierto que no destaca una figura episcopal de la talla de Tello Téllez de Meneses en Palencia, pero la proyección de la sede arzobispal de Compostela se dejó sentir en la composición del cabildo salmantino. El relato cronístico de Lucas de Tuy atribuye el protagonismo de su fundación al rey Alfonso IX hacia 1218, pero la escasa documentación disponible para el período remite a Fernando III como primer agente de la configuración del Estudio salmantino como un órgano privilegiado y autónomo, así lo definía cuando confirmaba en 1243 su "fuero exento" ${ }^{\prime 5}$. Por entonces, el pago de los maestros provenía de las tercias de la fábrica de las iglesias de la diócesis de las que el rey disfrutaba por concesión pontificia. Con todo, no es posible hablar de una madurez corporativa hasta la intervención de Alfonso X quien dotó al Estudio de un estatuto organizativo (Carta magna, 1254) y de rentas reales para sufragar los salarios de 11 catedráticos y cuatro oficiales (2.500 maravedíes de oro anuales). Aunque esta cantidad ascendió en 1286 a 11.600 maravedíes, apenas cubría las necesidades de los docentes ${ }^{6}$. Ahondó también en las exenciones de impuestos municipales sobre los artículos de alimentación ${ }^{7}$. Con el beneplácito del Obispo y el cabildo, la protección real contribuyó a asentar su sanción pontificia. Alfonso X obtuvo del Papa Alejandro IV en 1255 la bula que lo convertía en Estudio general (validez universal de sus grados) ${ }^{8}$. A pesar del fuero y de

\footnotetext{
${ }^{4}$ Gonzalo Martínez Díez, 68-69.

${ }^{5}$ Fernando III, 06/04/1243, ed. de Enrique Esperabé Arteaga, Historia pragmática e interna de la Universidad de Salamanca, Vol. I (Salamanca, 1914): I, 19 y 12/03/1252, 20: Fernando III exime de impuestos a los estudiantes de Salamanca.

${ }^{6}$ Alfonso X, Carta magna, 08/05/1254, Vicente Beltrán de Heredia, CUS I, doc. 23, 604.

${ }^{7}$ Reales Cédulas de Alfonso X, ed. Esperabé Arteaga, vol. I, doc. IV (1267), 23; doc. V (1271), 24 y doc. VI (1276), 25.

${ }^{8}$ Bula de Alejandro IV, 22/09/1255, ed. de Vicente Beltrán de Heredia, Bulario de la Universidad de Salamanca, 1219-1549 (en adelante, BUS), I, (Salamanca: Universidad de Salamanca, 1966), doc. 15, 322.
} 
la dotación financiera que la monarquía le suministró, el Estudio salmantino se configurará como una universidad marcadamente pontificia y eclesiástica. La jurisdicción del Estudio estaría en manos del maestrescuela de la catedral al contrario de lo que sucedió en la universidad de Valladolid y en las universidades de la Corona de Aragón donde la figura de rector asumió las competencias jurisdiccionales.

Ciertamente y, a pesar de haberse sustentado también con rentas reales (procedentes de los diezmos de la Iglesia), la configuración de la universidad de Valladolid presenta un rasgo que la diferencia de las castellanas de Palencia y Salamanca, y la acerca al modelo de las universidades de la Corona de Aragón sin ser el mismo. Se trata del papel que jugó el concejo en la administración y cobro de las rentas fijadas por la Corona para el pago de los salarios de los maestros. El Estudio no fue elevado a la categoría de Estudio general hasta 1346 (bula de Clemente VI) pero se hallaba activo en las últimas décadas del siglo XIII. Por un documento de Fernando IV (1304) en el que ordena a los recaudadores del concejo de Valladolid que entreguen al Estudio una renta fija anual para su sustento (20.000 maravedíes sobre las tercias reales del Obispado de Palencia), sabemos que ya su padre, Sancho IV, había realizado donaciones de las tercias reales en la villa de Valladolid y sus aldeas. Es decir, el concejo administraría las rentas concedidas al Estudio por delegación real ${ }^{9}$.

En la Corona de Aragón los gobiernos municipales que hasta el siglo XIV se habían resistido a integrar dentro de sus ciudades una corporación autónoma que escapaba a su control tomaron la iniciativa en la fundación de las dos primeras universidades. En realidad, solo Lérida (1300) y Huesca (1354) lograron obtener sanción pontificia durante la Baja Edad Media. Los monarcas aragoneses tomaron el testigo de la iniciativa y solicitaron al Papado la autorización para crear en su reino Estudios generales, pero no los dotaron con fondos reales. Jaime II en el estatuto que otorgó a la Universidad de Lérida tras su fundación confió a los paheres de la ciudad su financiación y el nombramiento de maestros. Imitando el modelo boloñés de corporación de escolares juristas, entregó al rector elegido por ellos la jurisdicción del Estudio. El rey había delegado, de este modo, la facultad de ejercer justicia

${ }^{9}$ 24/03/1304, Elena Sánchez Movellán,"La época medieval" en Historia de la Universidad de Valladolid, José María Palomares (Coord.), (Valladolid: Universidad de Valladolid, 1989), 28: "Sabed que el rey, mi padre, hobo a pro e a buen recaudo se dus reino hacer mercedes a los lectores e estudiantes, conservadores e demás ministros del Estudio General de Valladolid de las tercias de dicha villa e su tierra, e más de las de Mocientes y Fuensaldaña". 
en el ámbito académico de acuerdo con los paheres y el obispo de la ciudad ${ }^{10}$. También Pedro IV entregó el gobierno de la Universidad de Huesca (1354) al municipio y le encargó su financiación ${ }^{11}$.

La hacienda de las universidades hispanas en los siglos XIV y XV: administración y fuentes de ingreso

El papel jugado por las instituciones laicas (monarquía y gobiernos concejiles) y eclesiásticas (Pontificado e Iglesia diocesana) durante el siglo XIII y la primera mitad del siglo XIV, sin duda, marcó el devenir bajomedieval de los Estudios generales hispanos. Se forjaron modelos de gestión de su hacienda con rasgos diferenciadores, de menor calado en los castellanos, y un modelo mixto en los aragoneses. No obstante, ambos modelos compartieron una debilidad endémica en su financiación.

\section{Corona de Castilla}

En la Corona de Castilla solo Salamanca y Valladolid contaron con Estudios generales que desarrollaron su juventud y primera madurez en los siglos XIV y XV. Apenas disponemos de indicios sobre la formación del patrimonio bajomedieval de ambas. De hecho, desarrollaron su actividad en inmuebles propiedad del cabildo catedralicio. La dotación financiera de ambas continuó descansando en rentas de origen eclesiástico, las tercias o tercera parte proveniente del diezmo destinada a la fábrica de las iglesias. Una parte de las tercias de la fábrica (es decir, el noveno del diezmo) solían destinarlos papas y reyes a la guerra contra los infieles. La recaudación y distribución entre los miembros del Estudio de la tercia de las tercias de la fábrica de las iglesias de las dos diócesis fue otorgada por los monarcas a los concejos de Salamanca y Valladolid.

${ }^{10}$ Mariano Peset, "La fundación y el fuero universitario de Lérida”, Hispania no 58/2 (1998): 519-520.

${ }^{11}$ Isabel Falcón, María Luisa Ledesma, Carmen Orcastegui y Esteban Sarasa, "Las universidades en el reino de Aragón (Huesca y Zaragoza) y de Lérida en la Edad Media" en Homenaje de la Universidad de Valladolid a la de Bolonia en su IX centenario, (Valladolid: Universidad de Valladolid), 87. 
Salamanca: rentas eclesiásticas y paulatina intervención regia al final del XV

Fernando IV reguló en 1300 la recaudación y distribución de las tercias del Estudio de Salamanca. Estas serían puestas en arriendo cada año por el obispo/cabildo catedralicio y los oficiales conservadores del concejo nombrados por el rey ${ }^{12}$. Los testimonios sobre la concesión pontificia por trienios de las tercias y las dificultades de la recaudación en momentos de crisis se suceden a lo largo del siglo XIV. Fernando IV obtuvo de Bonifacio VIII una prórroga en 1301 para seguir cobrando las tercias de las fábricas de las Iglesias en Castilla y otra de Clemente V en 1313 de la tercera parte de las tercias de la fábrica de la diócesis. Esta concesión supuso además el desligamiento de las tercias de la universidad de aquellas que se concedían a los reyes para la guerra contra el infiel ${ }^{13}$. Entre medias, hubo una crisis agraria (1302-1305) que culminó con la suspensión de las mismas y la consiguiente falta de dotación para los salarios de los maestros. El concejo acudió en su ayuda poniendo en 1306 un tributo sobre la tierra de 12.000 maravedíes y el cabildo se mostró también dispuesto a colaborar por iniciativa propia y no por mandado del rey $^{14}$. Nuevas calamidades sobrevinieron entre 1312 y 1325, intensificadas por la inestabilidad política que prosiguió a la muerte de María de Molina (+1321), y que debieron provocar la suspensión de las clases puesto que, por entonces, la concesión que había hecho Clemente V en 1313 resultaba insuficiente para sufragar a los maestros ${ }^{15}$. Prueba de la anarquía reinante es que, un año antes de que Alfonso XI llegase al trono (1325), los clérigos de Alba de Tormes se habían negado a entregar la parte de las tercias que les correspondía ${ }^{16}$. Las contribuciones debidas para financiar la guerra de Granada empeoraron la penuria de estas décadas centrales del siglo XIV. Un leve alivio se produjo en 1335 cuando el Papa Benedicto XIII renovó al rey de Castilla la concesión de su antecesor de la décima de las rentas eclesiásticas y de dos partes de la fábrica de las Iglesias por un cuatrienio, esta promesa persistiría si no se produjeran treguas en la guerra de Granda. Circunstancia que sobrevino, por lo que el pontífice hubo de otorgar una prórroga de un

${ }^{12}$ CUS, I,07/08/1300, doc.46, 626.

${ }^{13}$ BUS, I, 16/09/1301, doc. 22. y 14/10/1313, doc. 24, 330. Antonio García y García, La Universidad de Salamanca. Historia y proyecciones, I, en M. Fernández Álvarez. L. Robles Carcedo y L. E. Rodríguez San Pedro (eds.), (Salamanca: Universidad de Salamanca, 1989), 22.

${ }^{14}$ CUS, I, 09/01/1306, doc. 48, 627.

${ }^{15}$ CUS, I, 117.

${ }^{16}$ CUS, I, 121. 
año para completar el cuatrienio ${ }^{17}$. Además, puede considerarse esta concesión como un precedente de la donación que Clemente VII hizo al rey Juan I en 1381 de un tercio de las rentas de todo el reino por haberle apoyado en el contexto del Cisma de Aviñón; del cual el monarca traspasó a la universidad el tercio correspondiente a la ciudad de Salamanca y su término. Con ello, la institución se aseguró una donación estable de 20.000 maravedís anuales ${ }^{18}$.

Dentro de la estructura jerárquica del Estudio salmantino el órgano administrativo-económico principal era el claustro de Diputados (rector, diputados doctores y no doctores, y maestrescuela), del cual dependía el arca de la universidad, la concesión de préstamos y la rendición última de las cuentas. El maestrescuela era uno de los tres clavarios, junto con el obispo/ cabildo y los oficiales del concejo nombrados por el rey (conservadores) que custodiaban las tres llaves del arca que se encontraba en dependencias catedralicias o en casa del bedel. El claustro de consiliarios (rector y consiliarios) elegían al administrador del Estudio que gestionaría los ingresos, ayudado por un grupo de oficiales del arca, los gastos y pagaría los salarios, debiendo dar cuenta de su gestión anualmente. Las fuentes de ingreso principales eran las provenientes de las tercias, a las que se unían algunas rentas, multas cobradas y la devolución de préstamos realizados por la universidad. La gestión de las tercias era compleja, éstas eran puestas en pública almoneda cada año. El control de los arrendadores y las cantidades que deberían entregar en tres plazos competía al administrador, quien de forma privada llevaba cuentas de ello por lo que no se han conservado pruebas documentales. La gestión de cobros y pagos cotidianos a cargo del administrador requería una organización contable amplia que no se recoge en los Libros de rentas y tercias conservados. En el siglo XV los adjudicatarios de estas rentas eclesiásticas se repartían en cerca de 300 aldeas integradas en cuatro villas con su tierra (Ledesma, Alba, Salvatierra y Miranda) y en los denominados cuartos (el de Val de Villoria, el de Almunia, el de Caños y el de Peña del Rey), a lo que hay que añadir Medina del Campo fuera de la diócesis ${ }^{19}$. El análisis de los remates finales en las almonedas públicas que tuvieron lugar entre 1403 y 1448 ha puesto de manifiesto que las fluctuaciones anuales fueron similares para cada fuente de las tercias. El grado de inflación fue significativo durante las cuatro crisis estacionales documentadas entre 1437 y 1442 . Generalmen-

\footnotetext{
${ }^{17}$ BUS, I, 12/04/1335, doc. 29, 336.

${ }^{18}$ CUS, I, 122.

${ }^{19}$ Fernando Martín Lamouroux, La revelación contable en la Salamanca histórica, (Salamanca: Diputación de Salamanca, 1988), 38-42.
} 
te, los administradores pagaban menos de lo que ingresaban, entregaban las cuentas a veces con años de retraso. De ahí, que en los Libros de claustros del siglo XV puedan encontrase requerimientos al administrador para que se entregase lo adeudado (en 1488 se le requirieron 100.000 maravedís). A pesar de estos retrasos, la recaudación funcionaba ${ }^{20}$.

Entre finales del siglo XIV y las décadas iniciales del siglo XV la Universidad de Salamanca se benefició de forma especial de la protección de dos pontífices. La historiografía ha considerado a Benedicto XIII como restaurador de la universidad salmantina, debido al efecto que las constituciones que le otorgó en 1411 tuvieron en su desarrollo durante gran parte del siglo XV. En las mismas, se aprecia el interés del pontífice por introducir rigor en el sistema de administración de la hacienda académica y fiscalizar los ingresos y gasto ${ }^{21}$. Reguló el sueldo de los maestros de derecho, medicina, teología y la facultad de Artes en el título segundo, al tiempo que concedió a los académicos un indulto para que pudiesen disfrutar durante un septenio de sus beneficios eclesiásticos, mientras estuviesen cursando sus estudios ${ }^{22}$. Intervino en los conflictos surgidos entre el Arzobispo de Santiago y la universidad a causa del nombramiento del administrador del Estudio (1413), reforzando el derecho del primero (1419) ${ }^{23}$. Su política para con la universidad salmantina se orientó, sobre todo, a salvaguardar su débil financiación y a orientar el superávit hacía la inversión en infraestructura, como muestran las bulas que otorgó en 1413. En la primera dirección fue la ratificación que hizo de las dos terceras partes de la renta de la fábrica de Almuña, Baños y Peña del Rey. Las rentas recaudadas en la segunda mitad del primer decenio del siglo $\mathrm{XV}$, según algunas noticias aisladas, oscilaban entre 160.000 y 180.000 maravedíes y debían cubrir ajustadamente los gastos ${ }^{24}$. En la segunda dirección fueron tres bulas, la de 1413 que obligó a depositar en el arca del Estudio el remanente para dedicarlo al pago de las suplencias de los catedráticos, ${ }^{25} \mathrm{y}$ las dos que reclamaban a los arrendatarios del cobro de las rentas del Estudio (adeudaban 2000 florines) para invertirlo en la construcción del edificio de las escuelas mayores (previsto en las constituciones de 1411) y en una

${ }^{20}$ Idem, 165 y 228.

${ }^{21}$ Antonio García y García, Historia de la Universidad de Salamanca, 42.

${ }^{22}$ BUS, II,26/07/1411, doc.,.444, constitución 2 y doc. 443, 24-25.

${ }^{23}$ BUS, II, 12/01/1419, doc. 571, 195-196.

${ }^{24}$ BUS, II, 31/03/1416, doc. 515, 82 y CUS, I, 1405-1408, doc. 82, 372: en este trienio la suma de ingresos anual fue de 53.00.188.671 y 169.351 maravedíes respectivamente.

${ }^{25}$ BUS, II, 03/07/1413, doc. 476, 56: se regula también las tasas de alquiler de casas en la ciudad a los miembros del Estudio y el aumento del salario de los catedráticos de cánones y leyes. 
librería. En la misma línea, fue la concesión de indulgencias a los que ayudasen a sostener el hospital de la universidad ${ }^{26}$.

Mayor trascendencia tendrían en el devenir de la institución las constituciones aprobadas por Martín V en 1422, vigentes hasta las reformas del siglo XVIII. La corporación consideraba obsoletas y demasiado severas las constituciones de Benedicto XIII por las numerosas censuras que imponían. Por ello, elaboró unas nuevas que presentó a Martín V para ser aprobadas con resultado positivo. Eran muy similares a las de Benedicto XIII, tan solo modificaron y completaron algunas de sus disposiciones. En lo relativo a la gestión económica, las constituciones octava, novena y décima reglamentaban el cargo de administrador de rentas o mayordomo que, a partir de entonces, sería propuesto por la universidad y nombrado por el Arzobispo de Toledo. En el siglo XVI esta figura se desdobló, mientras que el administrador se transformó en juez de rentas, el mayordomo (elegido por el claustro pleno) se encargaría de la gestión patrimonial ${ }^{27}$. La pérdida de un control directo sobre las rentas por el prelado provocó su protesta ante el Papa y un pleito contra la universidad. ${ }^{28}$. La constitución veintiuno regulaba la tasación de alquileres de casas a universitarios y la treinta la administración de las tercias eclesiásticas y la función del administrador. Las rentas recaudadas deberían ser invertidas en salarios, en la compra de libros y en la dotación de edificios para las escuelas y la biblioteca. Una vez cubiertos los gastos, si quedaba remanente (residuo), la mitad se depositaria en el arca para gastos imprevistos y la otra mitad se distribuiría ente lo catedráticos vitalicios ${ }^{29}$. Las constituciones vinieron precedidas de la concesión del Martín V al rey Juan II de las tercias de la fábrica de las iglesias para la guerra contra el infiel con algunas excepciones, una ellas fue la de las tercias reservadas a la universidad $(1421)^{30}$. Testimonios fragmentados revelan que las dificultades para la recaudación de las tercias del Estudio continuaron presentando dificulta$\operatorname{des}^{31}$. En la misma línea de protección de la institución, Eugenio IV confirmó

${ }^{26}$ BUS, II, 13/09/1413, doc. 480 y doc. 481, 60-61.

${ }^{27}$ Mariano Peset, "La organización de las universidades españolas en la edad moderna”, 78.

${ }^{28}$ BUS, II, 20/02/1422, doc. 647, 235. El apoyo de Eugenio IV al arzobispo concluyó con la muerte del primero (1445) y el retorno a la constitución original de 1422.

${ }^{29}$ BUS, II, 20/02/1422, doc. 647, 185 y 201-220. Luis Enrique Rodríguez-San Pedro Bezares, La Universidad de Salamanca en el primer renacimiento (1380-1516), (Salamanca: Ayuntamiento de Salamanca, 2013), 28-29.

${ }^{30}$ BUS, II, 08/10/1421, doc. 638, 169: si bien una vez cada 20 años la mitad se destinarían a reparación de iglesias y la otra mitad a la Cámara apostólica.

${ }^{31}$ CUS, I, 17/11/1439, doc. 99, 686: mandamiento del señor de Valdecorneja al concejo de Alba de Tormes para que den facilidades al administrador del Estudio en la recaudación de las 
en 1432 el privilegio para los universitarios de percibir íntegros sus beneficios eclesiásticos durante el tiempo de permanencia en el Estudio ${ }^{32}$.

En las constituciones de Benedicto XIII (1411) se menciona otra de las fuentes de ingreso que tuvo el personal académico, la colecta o pago que los maestros recibían de los estudiantes. La información sobre las misma es muy escasa, pudieron introducirse a finales del siglo XIV y existían todavía en 1466, pues disponemos de una referencia a un estatuto de colectas en ese momento. En cualquier caso, es posible documentar que fueron suprimidas en $1480^{33}$.

A partir de la proyección que Benedicto XIII hiciera en sus constituciones de la construcción de 7 aulas (cuatro para juristas y tres para teólogos, médicos y filósofos) se advierte una política de dotación de infraestructuras propias de la universidad ${ }^{34}$. En 1414 y en 1418 el claustro adquiere solares y casas en la Rúa Nueva para construir unas Escuelas mayores que albergasen las escuelas de leyes, cánones y medicina, las cuales hasta entonces se encontraban en casas alquiladas al cabildo catedralicio ${ }^{35}$. Se cree que el edificio de las Escuelas mayores se finalizó hacia 1420, lo cual permitiría a la universidad ganar independencia con relación al cabildo catedralicio. En la Rúa Nueva se encontraba también el Hospital de Santo Tomás conocido como Hospital del Estudio. En 1427 precisamente la universidad recibió una donación de casas corral en dicha calle que habían sido del hospital. Por su parte, las nuevas Escuelas de Gramática o Escuelas menores, antaño ubicadas en casas del cabildo cerca de la Iglesia de San Vicente (1417), comenzaron a construirse en 1428 a partir de la adquisición de unos suelos pudiera ser que cerca de San Bartoloméz ${ }^{36}$.

El avituallamiento del personal académico provocó algún conflicto con el concejo y fue objeto de regulación por ello. En 1388 el concejo estableció

tercias del Estudio en la villa y aldeas. CUS, II, 22/08/1469, doc. 143, 65: proceso contra el regidor de Bobadilla y el comendador en Villoria por impedir la cobranza de las tercias del Estudio.

${ }^{32}$ BUS, II, 24/02/1432, doc. 837, 354.

${ }^{33}$ BUS, I, 75.

${ }^{34}$ BUS, II,26/07/1411, doc..444, 25-36.

${ }^{35}$ CUS, I, 01/09/1414, doc. 85, 664: adquisición de estas casas a cambio de una renta anual de 3.300 maravedíes. Ángel Vaca Lorenzo, Diplomatario del Archivo de la Universidad de Salamanca, (Salamanca: Ediciones Universidad de Salamanca, 1996), doc. 4: se adquieren casas en la Rúa Nueva a cambio de una renta. Sabemos que en 1378 las Escuelas de Leyes y de Cánones estaban en casas arrendadas al cabildo, CUS, I, 18/08/1378, doc. 71, 647: Las Escuelas de Decretales estaban las casas que el cabildo había arrendado al bedel. Si éste se comprometía a restar de la renta 40 maravedíes anuales, el bedel acometería obras para acondicionarlo con bancos para 200 escolares, al igual que se había hecho con la Escuela de Leyes.

${ }^{36}$ 26/10/1427, Ángel Vaca, Diplomatario, doc. 10. CUS, I, 24/09/1417, doc. 88, 667. Ángel Vaca, Diplomatario, 17/08/1428, doc. 15. 
algunas exacciones sobre el pan, el vino y la carne. Consecuencia de ello debió ser el pleito que se entabló entre el Estudio y el concejo en 1418 con la intervención del rey. En 1421 se alcanzó un acuerdo, según el cual los universitarios y sus familiares podrían introducir vino para sus bodegas, siempre que no fuera para vender. El Estudio tenía su propia panera para vender trigo, sin embargo, no parece que disfrutase de una carnicería propia pues la requirió al corregidor de la ciudad en $1497^{37}$.

Las tres últimas décadas del siglo XV se caracterizaron por el creciente intervencionismo de los Reyes Católicos en la Universidad como prueba el nombramiento de un visitador y de conservadores del Estudio entre 1476 y 1484 por la reina Isabel $\mathrm{I}^{38}$. Estas visitas, expresión del ejercicio del derecho de patronato regio sobre la universidad, fueron constantes en el siglo XVI, llegando incluso a influir en la modificación de sus constituciones ${ }^{39}$. Noticias aisladas como la de 1473 hablan de un remanente en el saldo de las cuentas anuales (582.268 maravedíes) ${ }^{40}$ y de adquisición de casas en propiedad por la institución, sobre todo, en la Rúa Nueva donde se encontraban las Escuelas mayores ${ }^{41}$. Sin embargo, los viejos problemas con la recaudación de las rentas persistieron ${ }^{42}$. El pleito que el Estudio mantuvo con el cabildo por los derechos de ambos en los diezmos de la fábrica de la catedral finalizó con

37 Octubre de 1388, Ángel Vaca, Diplomatario, doc. 1, doc. 4 (30/09/1418), doc. 7 (2324/09/1421): "pueden meter ellos, o en otro por su mandato en la dicha çibdat, sin pena alguna, vino blanco e tinto, lo que ovieren menester para su provisión e mantenimiento de sus familiares continuos comensales, con un alvalá de un regidor qualuier".

${ }^{38}$ CUS, II, 08/10/1476, doc. 156, 74: la reina Isabel perdona al Marqués de Villena y a sus parientes y les restituye la conservaduría del Estudio; 31/12/1477, doc. 160, 76: Diego de Tejada presenta carta de los Reyes Católicos para ser proveído de la conservaduría; 23/11/1478, doc. 164, 78: Juan de Villafuerte presenta carta de la conservaduría que le hicieron los reyes; 08/02/1484, doc. 199, 130: confirmación por los reyes de la conservaduría para su doncel, Rodrigo Maldonado de Talavera.

${ }^{39}$ Mariano Peset, “La organización de las universidades españolas en la edad moderna”, 82.

${ }^{40}$ CUS, II, 09/11/1475, doc. 155, 73.

41 Ángel Vaca, Diplomatario, 05/11/1473, doc. 53: el cabildo vende a la universidad el censo anual de unas casas que le tenía arrendadas por 40.000 maravedíes. 25/10/1483, doc. 64: La universidad compra unas casas sitas en la Rúa Nueva próximas a las Escuelas menores por 70.000 maravedíes. 19/10/1487, doc. 74: el vicario del administrador del Obispado de Salamanca autoriza a Juan Pereira, arcediano de Nájera, a dar a la universidad en enfiteusis una casas sita en la Rúa nueva frente a las Escuelas mayores por una renta anual de 1.500 maravedíes.

42 Ángel Vaca, Diplomatario, 11/07/1468, doc. 47: Rodrigo de Bobadilla, regidor de Medina del Campo y señor de Bobadilla jura no ocupar ni embargar las tercias que la universidad poseía en Bobadilla. CUS, II, 21/08/1478, doc. 161, 77: que el alcalde de Monleón permita cobrar las tercias del Estudio en aquella vicaria. 
una sentencia que reconocía al primero el noveno de los diezmos de Ledesma, Miranda de Castañar, Alba, Medina del Campo y Salvatierra junto con los de Valdoba y Monleón ${ }^{43}$. Por otra parte, las deudas que los administradores del Estudio tendían a contraer tiene su máxima expresión durante las dos últimas décadas del siglo XV en el administrador Diego Ruíz de Camargo. A su muerte, la universidad entabló un pleito con su hijo al que embargó bienes por no haber saldado la deuda de 343. 671 maravedíes que su padre dejo a deber a la Universidad, dada su posición de máximo responsable de la recaudación anual de las rentas de la misma ${ }^{44}$.

Valladolid: tercias reales y administración municipal

La villa de Valladolid pertenecía al Obispado de Palencia, aunque su Iglesia colegial de Santa María disfrutaba de un privilegio de exención de jurisdicción y en el siglo XIII todavía no poseía el rango de ciudad. Sin embargo, se había producido una diversificación de la actividad económica y la presencia frecuente de la corte real favoreció la instalación de órganos de la administración de la monarquía. Se sabe que en la segunda mitad del siglo XIII existía un Estudio particular en la villa por la referencia que hace al mismo Sancho IV en 1293 cuando funda una institución similar en Alcalá de Henares ${ }^{45}$, pero tendría que esperar hasta 1346 para ser elevado a la categoría de Estudio general por bula de Clemente VI. El pontífice reforzó la financiación del Estudio vallisoletano con la concesión durante 6 años de dos partes de las tercias de la fábrica de la Catedral y diócesis de Palencia para sufragar los salarios de los catedráticos, período durante el cual el personal del Estudio podría disfrutar de beneficios eclesiásticos sin residir en ellos ${ }^{46}$.

Lo ingresos bajomedievales del Estudio de Valladolid se basaron en el siglo XIV en las rentas concedidas por reyes y papas sobre las tercias de la diócesis de Palencia. Los reyes de Castilla disfrutaron de una parte del tercio

\footnotetext{
${ }^{43}$ Ángel Vaca, Diplomatario, 08/02/1481, doc. 61.

${ }^{44}$ Ángel Vaca, Diplomatario, 26/08/1481, doc. 80.

${ }^{45}$ Mercedes Gaibrois, Historia del reinado de Sancho IV de Castilla, (Madrid : Tip. de la Revista de Archivos, Bibliotecas y Museos, 1922-1928), Vol III, doc. 479.

${ }^{46}$ BUS, III, 31/07/1346, doc. 1407, 345. La bula original de Clemente VI se perdió por lo que la Universidad solicitó a Clemente VII una copia en 1384 que incluye y confirma la anterior. Bulario de la Universidad de Valladolid, eds. Ma Ángeles Díez Rabadán, Ana I. Martinez Ferrerira y Miguel Angel Gónzalez Manjarres ,(Valladolid: Universidad de Valladolid, 2006), doc. 1, 36-37.
} 
del diezmo eclesiástico que en principio estaba reservado a la fábrica de la iglesia. Los monarcas fijaron las rentas y entregaron al concejo de Valladolid su recaudación y la administración de la universidad, para lo cual nombraron unos oficiales o conservadores. En Valladolid estos fueron dos regidores del concejo pertenecientes a los dos grandes linajes de la oligarquía urbana, los Reoyo y los Tovar. El documento de Fernando IV de 1304, en el que instaba a los oficiales del concejo de Valladolid a entregar al Estudio los 20.000 maravedíes anuales donados por el monarca y derivados de varios tributos reales, hacía referencia a las donaciones de su padre Sancho IV de tercias reales de la villa de Valladolid y su tierra, junto con las de Mucientes y Fuensaldaña. Alfonso XI aumentará esta donación en 1323 con 10.000 maravedíes anuales derivados del arriendo de las tercias reales de Valladolid y su tierra, situadas en pan, vino y ganado, destinados a pagar los salarios de los maestros lectores, de los conservadores y del bedel ${ }^{47}$.

En los últimos tres decenios del siglo XIV Enrique II y Juan I confirmaron los 20. 000 maravedíes de renta anual sobre las tercias de la villa y los lugares de Mucientes y Fuensaldaña, además de otorgarles la exención fiscal a los miembros ${ }^{48}$. Pero Juan I fundó el monasterio de San Benito en la ciudad que recibió la aprobación pontificia en 1387, cediéndole las tercias que tenía asignadas al Estudio. Ante las protestas del Estudio, su sucesor Enrique III le recompensó con la concesión de las tercias de los arciprestazgos de Portillo y Cevico de la Torre. La universidad se quejó a Enrique III de que los arrendadores le impedían la cobranza de dichas tercias, alegando que valían más de los 20.000 maravedís fijados; a lo cual el monarca respondió que debían ser percibidas por la misma, fuere cual fuere su valor ${ }^{49}$. Además, en 1404 destinó las tercias de los dos arciprestazgos a la creación de tres nuevas cátedras para asegurar los salarios de sus titulare ${ }^{50}$. La resistencia de las autoridades municipales a obedecer el privilegio de exención de impuestos para el Estudio motivó quejas ante rey por parte de este último y la búsqueda de protección real. La respuesta de los reyes fue positiva. Con Juan I lograron

${ }^{47}$ Elena Sánchez Movellán, Historia de la Universidad de Valladolid, (Valladolid: Universidad de Valladolid, 1989), vol. 1, 28.

${ }^{48}$ Vicente Vázquez de Figueroa, Libro Becerro de esta Real Universidad de Valladolid (1757). Completado con notas de Mariano Alcocer, Francisco Fernández Moreno y Calixto Valverde y Valverde, (Valladolid, 1919), 20/12/1367, 204-205. Mariano Alcocer, Historia de la Universidad de Valladolid. Bulas apostólicas y privilegios reales, (Valladolid, 1919), vol. II, 22/12/1379, doc. $3,11$.

${ }^{49}$ Vicente Vázquez de Figueroa, Libro Becerro de esta Real Universidad de Valladolid, 205. Mariano Alcocer, Bulas apostólicas y privilegios reales, II, Enrique III, 1404, doc. 5, 15.

${ }^{50}$ Vicente Vázquez de Figueroa, Libro Becerro de esta Real Universidad de Valladolid, 206. 
los miembros del Estudio la exención de hospedaje en 1379 y con Juan II en 1431 de acudir a la guerra de Granada ${ }^{51}$. La protección real no estuvo exenta de conflictos. Enrique III (1390-1406) devolvió al Estudio las rentas de que le había privado en beneficio del monasterio de San Benito, pero con la condición que debían entregar cada año 6000 maravedíes a Diego Meléndez de Valdés, debido a una merced real que este personaje había tenido anteriormente sobre las tercias ${ }^{52}$.

La obediencia de Castilla a los Papas de Aviñón durante el Cisma pontificio redundaría en la concesión por Benedicto XIII en 1416 de dos partes de las tercias de los arciprestazgos de Cevico y Portillo, a cambio de que el Estudio se rigiese por las constituciones que el pontífice había otorgado a Salamanca $(1411)^{53}$. Contrapartida que el Estudio de Valladolid aceptó pero no cumplió ${ }^{54}$ pues suponía una mayor intervención de los conservadores del Estudio, es decir, de la oligarquía urbana del concejo, en la asignación de cátedras. Benedicto XIII reaccionó decretando el embargo de las tercias del Estudio de los arciprestazgos de Cevico y Portillo, pero acabo levantado dicho secuestro en 1417 sin lograr introducir las nuevas constituciones ${ }^{55}$. Martín $\mathrm{V}$ tuvo también que transigir, en 1418 ordenó levantar cualquier secuestro sobre dichas tercias y confirmó los estatutos antiguos de la universidad ${ }^{56}$. La búsqueda de autonomía por parte de la universidad de Valladolid descansó en la obtención de la protección de la monarquía frente a la oligarquía urbana del concejo que trataba de controlarla. Por lo demás, los reyes del siglo XV mantuvieron las rentas reales destinadas al Estudio general aunque los ingresos debieron ser modestos. Así, en 1498 para fundar dos nuevas cátedras, una de Decreto y otra de Decretales, los Reyes católicos facultaron a la universidad a dividir en dos el salario de la Cátedra de Decreto (50.000 maravedíes $)^{57}$. Durante su reinado, además, la universidad recibió el apoyo regio ante los intentos del corregidor y otros oficiales de justicia de violar la autonomía jurisdiccional de que gozaban sus miembros ${ }^{58}$. En los comienzos de la edad moderna se configuró como un Estudio más jerarquizado y con

${ }^{51}$ Mariano Alcocer, Historia de la Universidad de Valladolid. Bulas apostólicas y privilegios reales, 22/12/1379, doc. 10, 11.

${ }^{52}$ Idem, 10/09/1437, doc. 21, 62. Incluye diversas provisiones de reyes anteriores.a

${ }^{53}$ Idem, Benedicto XIII, 02/06/1416, doc. 10, 19.

${ }^{54}$ Idem, Benedicto XIII, 12/05/1417, doc. 11, 31.

${ }^{55}$ Idem, Benedicto XIII, 18/06/1417, doc. 11, 31.

${ }^{56}$ Idem, Martín V, 08/07/1418, doc. 16, 43; 201/12/1418, doc. 17 y doc. 18, 45-47.

${ }^{57}$ Idem, doc. 31, 103.

${ }^{58}$ Elena Sánchez Movellán, Historia de la Universidad de Valladolid, vol. 1, 34. 
menor autonomía. Las constituciones del siglo XVI revelan su sometimiento al patronato regio ${ }^{59}$.

\section{Corona de Aragón}

El nacimiento de las universidades en la Corona de Aragón no se produjo hasta el siglo XIV y fue el fruto de una acción mancomunada entre la monarquía, los gobiernos municipales y la Iglesia. Las dinámicas oligarquías urbanas que controlaban los gobiernos de sus ciudades veían en esta institución como una amenaza para su autonomía. Solo dos ciudades, Lérida (1300) y Huesca (1354,) tuvieron un Estudio general con aprobación pontificia y desarrollo durante los siglos XIV y XV. Los Estudios aparecidos en las ciudades de Gerona, Mallorca, Barcelona y Valencia no lograron confirmación pontifica hasta los albores de la época moderna.

Lérida: financiación municipal exclusiva y fórmulas mixtas

A finales del siglo XIII Jaime II de Aragón con la mediación de los franciscanos dirigió a los paheres del gobierno municipal de Lérida una carta con la petición de crear un Estudio General en la ciudad (1293). Poco después, en 1297, recibió autorización pontificia para el proyecto y en 1300, ratificando el deseo del gobierno municipal, concedió al nuevo Estudio privilegio fundacional. La fundación del Estudio General fue acompañada de unas normas estatutarias aprobados casi de manera simultánea. El municipio de Lérida como partícipe del nacimiento de la institución retuvo un claro protagonismo en los aspectos relacionados con la su financiación y con el nombramiento de profesores ${ }^{60}$. Aunque el Papa deseaba que siguiera el modelo de la Universidad de Toulouse se inspirará en el modelo boloñés. Jaime II evitó, de este modo, que el Estudio quedase bajo el control exclusivo de la Iglesia y lo convirtió en una estructura de poder equilibrado, que fue la base de las universidades de la Corona de Aragón, bajo un amplio poder municipal ${ }^{61}$. El rey conservaría la facultad de intervención en la nueva universidad, pero la

\footnotetext{
${ }^{59}$ Mariano Peset, "La organización de las universidades españolas en la edad moderna”, 93.

${ }^{60}$ Joan J. Busqueta (ed.). Llibre de les Constitucions i Estatuts de l'Estudi General de Lleida, 29-30.

${ }^{61}$ Rafael Ramis Barceló, Estudios sobre la Universidad de Lérida, 18.
} 
jurisdicción de la misma correspondería al rector nombrado entre los estudiantes. En el privilegio fundacional se justifica la elección de Lérida por su posición central en los reinos de la Corona de Aragón, en cuyos territorios se le concedía el monopolio de la enseñanza superior que después no se cumplió $^{62}$. A diferencia de los que ocurrió en las universidades de Salamanca y Valladolid, el Estudio general de Lérida no fue dotado con rentas reales o pontificias propias. La pahería o gobierno municipal asumió la erección y sostenimiento del mismo. En el mes de septiembre del mismo año de la fundación (1300), el consejo general de la ciudad se reunió en la Seo y se obligó a pagar el salario de seis maestros y de un estacionario, así como a construir cuatro aulas y a facilitar vivienda a los estudiantes ${ }^{63}$.

Durante el período fundacional (1300-1319) se estableció una fórmula de financiación eclesiástico-municipal no exenta de dificultades por la falta de armonía. El Obispo y el cabildo llegaron a un acuerdo con los paheres para colaborar en el sostenimiento del Estudio. Para ello, crearon un impuesto que todos los clérigos de la diócesis deberían satisfacer so pena de excomunión. Por su parte, la ciudad estableció un impuesto municipal para pagar el salario de los profesores. El acuerdo funcionó entre 1300 y 1305 pero el Estudio hubo de cerrar en el quinquenio siguiente. Una nueva concordia ${ }^{64}$ permitió reabrirlo en 1310. La Pahería cedió al Obispo y cabildo el nombramiento de profesores durante diez años. Ambos deberían contribuir con 2.500 sueldos jaqueses (250 libras), cantidad que resultó ser suficiente para la plantilla inicial de siete catedráticos. En 1313 mediante una sentencia arbitral del monarca los paheres recuperaron el nombramiento de los catedráticos. Se allanó así el camino a una segunda etapa de financiación enteramente municipal (1319-1349). Para ello, sin autorización del monarca y burlando el fisco real, los paheres establecieron un impuesto sobre la venta del vino en la ciudad denominado la "libra del Estudio" (1 sueldo por cada 28 del valor del vino con una vigencia de 3 años). Pedro IV condonó esta irregularidad y concedió una prórroga del impuesto hasta 1359. Sin embargo, desde 1360 esta fuente de ingreso resultaba insuficiente debido al crecimiento de la plantilla. A pesar de los apoyos

${ }^{62}$ J. LLadanoa I Pujol, L'Estudi general de Lleida del 1430 al 1524, (Barcelona, 1970), 188, 210-212. y Mariano Peset,"La fundación y el fuero universitario de Lérida", Hispania 58I/2, no22 (1998): 519-520.

${ }^{63}$ Francesc Esteve Perendreu, El régimen jurídico del Estudio General de Lleida (s. XIIIXVIII), (Lleida: Pagès editors, 1992), 61-64.

${ }^{64}$ Roser Gort Riera, L'Estudi General de Lleida al segle XIV, (Lleida: Edicions de la Universitat de Lleida, 2016), 39: El obispo y cabildo de Lérida se comprometieron a proveer las cátedras durante 6 años, aportando la mitad del salario. 
recibidos de Pedro IV para acrecentar la recaudación, comenzaron a exigirse tallas o imposiciones a los profesores y estudiantes. Hacia 1378 el sistema de financiación municipal única se había resquebrajado ${ }^{65}$. En 1399 el Rey Martín el Humano promovió reformas fiscales para equilibrar el pago de imposiciones dedicadas a captar recursos para el Estudio. Para ello, estableció que los estudiantes deberían también pagar por una serie de artículos alimenticios. ${ }^{66}$

Durante el período del Cisma de Aviñón se volvió en cierto modo a la fórmula de financiación municipal y eclesiástica. Clemente VII le concedió al Rey Martín el Humano los denominados "legados inciertos de la diócesis" (provenientes de los beneficios eclesiásticos vacantes en la Provincia eclesiástica de Tarragona que alcanzaban en 1398 la suma de 4000 florines, es decir, unas 2000 libras) pero eran eventuales. Obtuvo también tres rótulos pontificios de expectativa de beneficios eclesiásticos para los miembros del Estudio que dan fe de su crecimiento $(1378,1387 \text { y } 1394)^{67}$. La pahería de Lérida estableció una imposición a los estudiantes de un dinero por cada libra de carne y, a pesar de la resistencia, se convirtió en una renta fija en el futuro. También Benedicto XIII favoreció al Estudio concediéndole 100 florines anuales sobre el decanato del cabildo de Lérida y una renta de 400 florines sobre los bienes legados por Berenguer Gallart (albaceazgo de Gallart). Además, intervino en la organización administrativa reduciendo el número de clavarios de seis a tres (uno por el Estudio, uno por el municipio y uno por el cabildo catedralicio). De este modo, al final del Cisma la Universidad de Lérida contaba con cinco fuentes de ingreso aseguradas que cubrirían la nómina de los profesores, sumando unos 970 florines: los tres que se acaban de mencionar ("libra de vino", "los legados inciertos", pensión anual del Decanato de Lérida y la pensión sobre el albaceazgo de Berenguer Gallart). A ello habría que sumar las colectas que cada catedrático podía recaudar de sus alumnos por las lecturas impartidas (estipuladas en estatutos fundacionales de 1300) y el bancaje, cantidad anual que se pagaba por sentarse en los bancos de las aulas ${ }^{68}$.

Hacia mediados del siglo XV (1447), el Obispo García Aznares emprende una reforma de los estatutos fundacionales del Estudio que en lo que se refiere a la financiación continúa nutriéndose de viejas fuentes imposi-

${ }^{65}$ Ramón Gayá, "Las rentas del Estudio General de Lérida", Analecta Sacra Tarraconensia, no 25 (1954): 293-303. Francesc Esteve Perendreu, El régimen jurídico del Estudio General de Lleida (s. XIII-XVIII),166-170.

${ }^{66}$ Rosert Gort Riera, L'Estudi General de Lleida al segle XIV, 45.

${ }^{67}$ Joan J. Busqueta, “Sobre l'Estudi General de Lleida a l'Edat Mitjana. Algunes quëstions", Millars: Espai i Història,no 46/1 (2019): 150-151.

${ }^{68}$ Ramón Gayá, “Las rentas del Estudio General de Lérida”, 308-315. 
tivas. Se añadió una donación del obispo de 50 florines, media porción de la Prepositura de la Sede que recibía el maestro de gramática y un nuevo albaceazgo (del maestro Juan de Prusia), con los cuales se alcanzaría la suma de 1.005 florines para cubrir los salarios de profesores. El Papa Calixto III favoreció al Estudio y le asignó, además, una renta de 100 florines. Desde mediados del siglo XV, Lérida sufrió de forma directa los embates de la guerra civil que enfrentó a Cataluña y al rey Juan II (1462-1472). Tras la rendición, el monarca embargó las rentas de la pahería y del Estudio general pero los paheres consiguieron que se respetase el privilegio de la universidad. Fue el comienzo de una larga decadencia pues se enfrentaron a la dificultad añadida de la competencia de la Universidad de Huesca que fue restaurada en este período por el Papa Paulo II a ruegos del monarca Juan II. Aunque lograron recuperar algunas fuentes de ingreso, el cobro de las demás no se restableció hasta 1553 por bula de Julio III ${ }^{69}$. El apoyo de la monarquía de que había disfrutado se fue diluyendo a causa de la atención prestada desde mediados del siglo XVI por los reyes a las universidades emergentes de Barcelona y Zaragoza. Tendencia que no excluyó la toma de medidas favorables a la Universidad de Lérida, defendida por Felipe II como sede universitaria tradicional ${ }^{70}$.

Huesca: insuficiente financiación municipal y débil apoyo eclesiástico

La segunda universidad en los territorios peninsulares de la Corona de Aragón fue Huesca. La iniciativa municipal, al igual que sucedió en otras universidades de estos reinos, caracterizó los comienzos de una institución cuya vida fue errática en la Baja Edad Media, debido precisamente a sus problemas de dotación financiera. Pedro IV, rompiendo el monopolio sobre la enseñanza superior que se había atribuido a la Universidad de Lérida y como respuesta a la petición de los jurados municipales, fundó el Estudio general de Huesca en 1354. Sin duda, el contexto político que llevó a Huesca a no jurar el privilegio de la Unión de los aragoneses (1287) en el pasado, pesó en esta decisión. El monarca les entregó el gobierno del Estudio y se reservó el derecho a promulgar estatutos. Como se ha observado que sucedió con el de Lérida, no le dotó con rentas reales por lo que la financiación del nuevo Estudio general recayó en el gobierno municipal de Huesca. El refrendo pontificio a esta nueva institución no llegó hasta 1465 lo que puede explicar la

\footnotetext{
${ }^{69}$ Ramón Gayá, "Las rentas del Estudio General de Lérida”, 318-328.

${ }^{70}$ Rafael Ramis Barceló. Estudios sobre la Universidad de Lérida, 23.
} 
ausencia de aportación eclesiástica. El municipio impuso un tributo sobre la carne que topó con la resistencia de los vecinos pero resultó ser insuficiente. Pedro IV intentó paliar la deficiencia financiera pidiendo a las aljamas judía y musulmana que contribuyeran con un impuesto pero la debilidad de la hacienda del Estudio culminó con su cierre entre finales del siglo XIV y comienzos de siglo XV. No se puede eludir que la protección de Fernando II a la universidad de Huesca suscitó recelos en el Estudio de Lérida que hasta ese momento se nutría también de estudiantes oscenses ${ }^{71}$.

La Universidad de Huesca hubo de ser refundada a comienzos del siglo $\mathrm{XV}$, esta vez de la mano del Obispo Fenollet y del cabildo catedralicio. Por otra parte, la confirmación pontificia de 1465 la equiparó en privilegios a la de Bolonia y a la de Lérida, además de facilitar financiación eclesiástica. El obispo y el cabildo de Huesca la dotaron en 1473 con las rentas de cuatro beneficios eclesiásticos. La junta de gobierno en la segunda mitad del siglo $\mathrm{XV}$ estuvo constituida por el obispo/cabildo, de una parte, y, de otra, por el concejo (un prior de los jurados y un ciudadano designado por el concejo). El concejo recurrió a los impuestos, imponiendo alguna sisa sobre productos y a finales del siglo XV el obispo aportó más rentas. Nada de ello debió fortalecer la endeble financiación de un Estudio general que hacía 1475 continuaba siendo modesto en número de estudiantes ${ }^{72}$.Por otro lado, Cataluña contaba para entonces con Estudios desprovistos todavía de refrendo pontificio pero con suficiente prestigio como para suponer una competencia. Es el caso del Estudio de Gerona aprobado por Alfonso V, del Estudio de artes y medicina de Barcelona promovido por Martín el Humano (privilegio fundacional de 1401) y del Estudio de Mallorca (Privilegio fundacional de Fernando el Católico, 1483). La protección que Fernando II ejerció sobre las universidades de la Corona de Aragón no bastó para acrecentar la importancia del Estudio general de Huesca en los decenios finales del siglo XV.

\section{Conclusión}

La escasez de documentación sobre el origen y evolución de las primeras universidades hispanas en el siglo XIII no permite establecer conclusiones defi-

${ }^{71}$ Ma Isabel Falcón, Ma Luisa Ledesma, Carmen Orcastegui y Esteban Sarasa, "Las universidades del reino de Aragón (Huesca y Zaragoza) y de Lérida en la Edad Media", 88-89.

${ }^{72}$ José María Lahoz Finestres, "Las intervenciones reales en la Universidad de Huesca (1354-1599)", El poder real en la Corona de Aragón. Congreso de Historia de la Corona de Aragón, vol. 5, (Zaragoza: Gobierno de Aragón, 1996), 441-445. 
nitivas sobre su infancia. El innegable protagonismo que la historiografía ha atribuido a los reyes Alfonso VIII y Alfonso IX en el surgimiento de las universidades de Palencia y Salamanca respectivamente, ha de ser matizado. Ambos fueron receptivos a las propuestas de los prelados que formaban parte del entorno real y sensibles al cado de cultivo cultural de las escuelas catedralicias existentes. Ciertamente, tomaron el testigo de estas iniciativas e impulsaron la mutación institucional que alumbró los Estudio generales. Ese apoyo político reforzado por la necesaria confirmación pontificia fue acompañado por una dotación financiera sustentada en rentas reales de origen eclesiástico, las tercias reales, (tercias del diezmo destinado a la fábrica de las iglesias de las diócesis de Palencia y Salamanca). Durante esta centuria sirvieron para sustentar el salario de los maestros. Los estudiantes, en su gran mayoría clérigos de órdenes menores, se valieron de los beneficios eclesiásticos anexos a esta condición para sufragar sus estudios. Sin embargo, a falta de mayores indicios, es posible aventurar que el Estudio de Palencia fue víctima de la prioridad que para los monarcas castellanos supuso completar la recuperación de la Meseta Sur bajo dominio musulmán. Una urgencia que ya no afectó al Estudio salmantino en las décadas centrales del siglo XIII cuando alcanzó una madurez corporativa que lo configuró como un Estudio marcadamente pontificio y eclesiástico (el maestrescuela, juez del Estudio, era además uno de los tres clavarios que custodiaban el arca de la universidad). En cambio, en la vecina Valladolid, cuyo Estudio se demoró en la obtención de la confirmación pontificia, el concejo asumió por delegación real el cobro y la administración de las rentas reales fijadas para la institución. Los oficiales del concejo encargados de esta tarea serían dos regidores que representaban a los linajes más importantes de la ciudad; en el futuro pondrían trabas a las exenciones de impuestos para los académicos e intentarían intervenir directamente en la provisión de cátedras.

En el siglo XIV, mientras que las haciendas universitarias de las universidades de Salamanca y Valladolid acusaban los vaivenes provocados por las crisis agrarias, las fluctuaciones de la moneda y el costo de la guerra de Granada, las universidades de la Corona de Aragón hicieron su entrada en la escena histórica como resultado de una acción mancomunada de los monarcas y los gobiernos municipales con el respaldo de sus iglesias diocesanas. De ahí, que desarrollasen un modelo de financiación mixta que, a diferencia de lo sucedido en Castilla, hizo recaer el peso de la misma en los gobiernos municipales y no contó con una dotación específica por parte de los reyes aragoneses, tampoco del Pontificado salvo de forma puntual. Solo los Estudios de Lérida (1300) y Huesca (1354) obtuvieron confirmación pontificia, 
convirtiéndose en Estudios generales en la Baja Edad Media. Su evolución en los siglos XIV y XV se vio lastrada por la dificultad de consolidar unos ingresos sostenidos mayormente en la imposición de tributos municipales a unas ciudades recelosas de los privilegios de la institución, y por la tensión con las autoridades eclesiásticas que exigían el control sobre el nombramiento de maestros a cambio del apoyo monetario. Las aportaciones papales en momentos críticos no impidieron los períodos de decadencia que, en el caso del Estudio de Lérida, se agravaron con la guerra civil catalana en la segunda mitad del siglo XV; y, en el caso de Huesca, hizo necesaria una refundación con financiación eclesiástica. Paralelamente, en la Corona de Castilla, la universidad de Valladolid con una hacienda modesta durante el siglo XV buscó la protección regia frente a las pretensiones de control sobre la misma de la oligarquía urbana. La universidad de Salamanca, por su parte, reguló constitucionalmente la gestión de su hacienda para salvaguardar su debilidad financiera, mantuvo las tercias reales como fuente principal de sostenimiento, aseguró el avituallamiento mediante la exención de impuestos concejiles sobre productos básicos y orientó el superávit a la dotación de una infraestructura propia (escuelas mayores y menores). Su marcada impronta pontificia y eclesiástica, garante de su protección, no impediría una creciente intervención de la monarquía en la institución que se intensificó con los Reyes Católicos en los albores de la Edad Moderna.

\section{Bibliografía}

ALCOCER, Mariano. Historia de la Universidad de Valladolid. Bulas apostólicas y privilegios reales, vol. II, Valladolid: Imprenta castellana, 1919.

BELTRÁN DE HEREDIA, VICENTE. Cartulario de la Universidad de Salamanca (1218-1600), I, Salamanca: Universidad de Salamanca, 1970.

- Cartulario de la Universidad de Salamanca (1218-1600), II, Salamanca: Universidad de Salamanca, 1970.

BELTRÁN DE HEREDIA, VICENTE. Bulario de la Universidad de Salamanca (1219-1549), I, Salamanca: Universidad de Salamanca, 1966.

- Bulario de la Universidad de Salamanca (1219-1549), II, Salamanca: Universidad de Salamanca, 1966.

- Bulario de la Universidad de Salamanca (1219-1549), III, Salamanca: Universidad de Salamanca, 1967.

BUSQUETA, JOAN J. (ed.). Llibre de les Constitucions i Estatuts de l'Estudi General de Lleida, Lleida, Universitat de Lleida: 2000. 
- "Sobre l'Estudi General de Lleida a l'Edat Mitjana. Algunes quëstions”. En Millars: Espai i Història, no 46/1 (2019):145-165.

DÍEZ RABADÁN, Ma ÁNGELES, MARTÍNEZ FERRERIA, ANA I. y GONZÁLEZ MANJARRÉS, MIGUEL ANGEL (Coords). Bulario de la Universidad de Valladolid, Valladolid: Universidad de Valladolid, 2006.

ESPERABÉ ARTEAGA, ENRIQUE. Historia pragmática e interna de la Universidad de Salamanca, Vol. I, Universidad de Salamanca: Salamanca, 1914.

FALCÓN, ISABEL; LEDESMA, Ma LUISA; ORCASTEGUI, CARMEN y SARASA, ESTEBAN. "Las universidades en el reino de Aragón (Huesca y Zaragoza) y de Lérida en la Edad Media”. En Estudios sobre los orígenes de las universidades españolas, Homenaje de la Universidad de Valladolid a la de Bolonia en su IX centenario, Valladolid: Universidad de Valladolid, 1988: 84-95.

GAIBROIS, MERCEDES, Historia del reinado de Sancho IV de Castilla, Madrid: Tip. de la Revista de Archivos, Bibliotecas y Museos, 1922-1928, 3 vols. GAYÁ, RAMÓN. "Las rentas del Estudio General de Lérida”. En Analecta Sacra Tarraconensia, nำ25 (1954): 293-338.

GARCÍA Y GARCÍA, ANTONIO, La Universidad de Salamanca. Historia y proyecciones, I, . En FERNÁNDEZ ÁLVAREZ, M, ROBLES CARCEDO, L. y RODRÍGUEZ SAN PEDRO, L. E.(eds.). Salamanca: Universidad de Salamanca, 1989.

GORT RIERA, ROSER, L'Estudi General de Lleida al segle XIV, Lleida: Edicions de la Universitat de Lleida, 2016.

LAHOZ FINESTRES, JOSÉ MARÍA. "Las intervenciones reales en la Universidad de Huesca (1354-1599)”. En El poder real en la Corona de Aragón. Congreso de Historia de la Corona de Aragón, vol. 5, Zaragoza: Gobierno de Aragón: 1996, 437-448.

LLADONOSA I PUJOL, JOSEP. L’Estudi general de Lleida del 1430 al 1524, Barcelona: Institut d'Estudis Catalans, 1970.

MARTÍN LAMOUROUX, FERNANDO. La revelación contable en la Salamanca histórica, Salamanca: Diputación de Salamanca, 1988.

MARTINEZ DÍEZ, GONZALO. "Palencia, primera universidad de España”. En El Estudio General de Palencia. Historia de oho siglos de la Universidad española, Margarita Torremocha Hernández (Coord.), Valladolid: Universidad de Valladolid-Instituto Universitario Simancas, 2012: 47-68.

PERENDREU, FRANCESC ESTEVE. El régimen jurídico del Estudio General de Lleida (s. XIII-XVIII), Lleida: Pagès editors, Collecció El Fil d'Ariadna, 1992. 
PESET, MARIANO. "La organización de las universidades españolas en la edad moderna" En Studi e Diritto nell'area mediterranea in età moderna, a cura di Andrea Romano, Rubbettino, 1993: 73-122.

- "La fundación y el fuero universitario de Lérida"- Hispania, no58/2 (1998):515-536. RODRÍGUEZ SAN PEDRO BEZARES, LUIS ENRIQUE. La Universidad de Salamanca en el primer renacimiento (1380-1516), Salamanca: Ayuntamiento de Salamanca, 2013.

RAMIS BARCELÓ, RAFAEL. Estudios sobre la Universidad de Lérida, Madrid: Dykinson, 2018.

SÁNCHEZ MOVELLÁN, ELENA. "La época medieval”. En Historia de la Universidad de Valladolid, Coordinado por José María Palomares, Valladolid: Universidad de Valladolid, 1989.

SAN MARTÍN PAYO, JESÚS. La antigua Universidad de Palencia, Madrid: Afrodisio Aguado, 1942.

VACA LORENZO, ÁNGEL. Diplomatario del Archivo de la Universidad de Salamanca, Salamanca: Ediciones Universidad Salamanca, 1996.

VÁZQUEZ DE FIGUEROA, Vicente, Libro Becerro de esta Real Universidad de Valladolid (1757). Completado con notas de Mariano Alcocer, Francisco Fernández Moreno y Calixto Valverde y Valverde, Valladolid, 1919. 